J. Electraanal Chem., 75 (1977) 507-522

○ Elsevier S̃equoia S.A., Lausanne - Printed in The Netherlands

\title{
ELECTROCHEMICAL REDUCTION OF SUBSTITUTED PYRIMIDINES IN ACETONITRILE *
}

\author{
JAMES E: O'REILLY \\ Department of Cherristry; Laiversity of Kentucky, Lexington, Ky, 40506 (U.S.A.) \\ PHILIP J. ELVING \\ Department of Chemistry, University of Michigan, Ann Arbor, Mich. 48109 (U.S.A.)
}

(Received 8th May 1976)

\begin{abstract}
Polarographic studies of several substituted pyrimidines were reinforced by the results from cyclic voltammetry, controlled-potential electrolysis, and spectrophotometric examination of electrolyzed solutions, as well as by the examination of model compounds. Pyrimidines substituted with non-reducible groups (amino, methyl) are reduced in a single, one-electron (1e), diffusion-controlled process, very similar to that for pyrimidine itself. Pyrimidine-4-carboxylic acid exhibits three reduction waves: a very drawn-out acidreduction wave with unusual properties and, at more negative potential, an adsorption prewave and a wave corresponding to the le reduction of the pyrimidine moiety. 2-Chloroand 2-bromopyrimidine each exhibit two polarographic waves; the furst, corresponding to irreversible scission of the carbon-halogen bond, has electrcchemical properties quite different from those normally expected; the second is due to reduction of the electrogenerated pyrimidine. Results are compared with those for the reduction of bromobutine, bromobenzene, and 2-bromopyridine.
\end{abstract}

\section{INTRODUCTION}

In the course of our investigations of the electrochemical reduction of azabenzenes and related compounds in nonaqueous media [1-4],the effects of various substituents on the basic reduction patterns of the azabenzene rings were investigated. The present paper sumriarizes the results obtained for the monoazine (pyridine) and, more particularly, for 1,3-diazine (pyrimidine). Pyridine is the parent ccmpound for the biologically important pyridine (nicotinamide) coenzymes, e.g., NAD ${ }^{+}$and NADP', and pyrimidine is the parent compound for the pyrimidines and purines found in the nucleic acids, ATP, harbituric acids and other biologically essential species. In these studies, some highly unusual results were Gitained on the carbon-halogen bond fission reaction for hal opyrimidines.

\footnotetext{
In honour of Dr. G.C. Barker'; 60th birthday.
} 
The polarographic and related behavior of pyrimidines and nicotinamides has been reviewed by the authors [5]- The phenomena and mecharisms for carbon-halogen bond fission have also been recently reviewed $[6,7,36]$. Czochralska and Wrona $[8,9]$ have investigated the polarographic behavior of halopyrimidines in aqueous buffered media.

Briefly summarized, in nonaqueous media, pyrimidine undergoes an initial reversible one-electron (1e) reduction to a radical anion which rapidly dimerizes; pyridine is apparently reduced in an overall $2 e$ ECE process involving $1 e$ reversible reduction to a radical anion, which abstracts a proton from the solvent and/or residual water to produce a free radical species that is unstable at the potential of its formation and is, consequently, immediately reduced in a second ie process. The situation in respect to the carbon-halogen $(C-X)$ scission is less clear; while the overall process observed is considered by most investigators to be a $\mathrm{Z} e$ one, there is some question as to the component steps involved.

(An ECE mechanism for a single polarographic wave refers to a process in which an electrochemical step involving electron transfer produces a species which then undergoes a chemical reaction to produce a product unstable at the potential, at ivhich it is formed, and consequently rapidly reduced in a second electrochemical reaction.)

\section{EXPERIMENTAL}

Chemicals were obtained from the sources indicated: 2,4-dimethoxypyrimidine (Cyclo Chemical); 5-methylpyrimidine (Nutritional Biochemicals); 4-methylpyrimidine and pyrimidine-4-carboxylic acia (Calbiochem); bromobenzene (Eastman); bromoblitane (J.T. Baker). 2-Aminopyrimidine (Eastman) was recrystallized once from water and twice from benzene. 2-Chloropyrimidine ( $\mathrm{K} \& \mathrm{~K}$ Laboratories) was recrystallized from isopentane four times to give white crystals: m.p. $63.5-64.5^{\circ} \mathrm{C}$ (literature [10] : $64.5-65.5^{\circ} \mathrm{C}$ ) (anal calc. for $\mathrm{C}_{4} \mathrm{H}_{3} \mathrm{~N}_{2} \mathrm{Cl}: \mathrm{C}, 41.95 ; \mathrm{H}, 2.61 ; \mathrm{N}, 24.46 ; \mathrm{Cl}, 30.95$; found: $\mathrm{C}, 41.80$; $\mathrm{H}, 2.67 ; \mathrm{N}, 24.39 ; \mathrm{Cl}, 31.08)$. 2-Bromopyrinidine was prepared according to

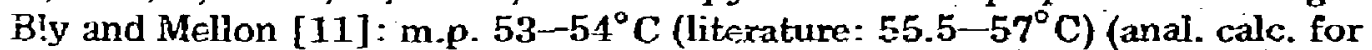
$\mathrm{C}_{4} \mathrm{H}_{3} \mathrm{~N}_{2} \mathrm{Br}: \mathrm{C}, 30.22 ; \mathrm{H}, 1.90 ; \mathrm{N}, 17.63 ; \mathrm{Br}, 50.26$; round: $\mathrm{C}, 30.40 ; \mathrm{H}, 1.94$; $\mathrm{N}, 17.75 ; \mathrm{Br}, 50.19$ ). Concentrations of stock solutions of pyrimidines were checked by means of reported molar absorptivizies [11,12].

Sources and pusification of other chemicals, apparatus, and electrochemical procedures have been describer: $[1,2,13]$.

Ali potentials were measured and, unless otherwise stated, are reported versus a $\mathrm{Ag} / 0.01 \mathrm{M} \mathrm{Ag}^{+}, 0.1 \mathrm{M}$ tetraethylammorium perchlorate (TEAP) in acetonitrile electrode, whose potential versus the aqueous SCE is $0.293 \mathrm{~V}$ $[1,14]$. Currents at the DME were measured as maximum currents on an undamped potentiostat; where necessary, as in the calculation of $\boldsymbol{I}_{\mathrm{d}}$ values, maximum currents were multiplied by $6 / 7$ to convert them to average currents. The background electrolyte was $0.1 \mathrm{M}$ TEAP. 


\section{RESULTS AND DFSCUSSION}

Fyrimidines, substituted with non-reducible groups such as amino or methyl, exhibit in zeetonitrile polarographic properties very similar to those for pyrimidine itself $[1 ; 2\}$, i.e., a single, 1e, diffusion-controlled wave ('lable 1 ). Since methyl and amino groups are electron-donating relative to hydroger, the half-wave potential $\left(E_{1 / 2}\right)$ values are more negative than $E_{1 / 2}$ for pyrimidine itself: 4-Methylpyrimidine has a more r.gative $E_{1 / 2}$ than the 5-methyl derivative because of the closer proximity of the substituent to the reduction site (the $3,4 \mathrm{~N}=\mathrm{C}$ double bond). In general, the cyclic voltammetric behavior of these compounds is much the same as that of pyrimidine itself.

2,4-Dinethoxypy rimidine, which is reduced at a quite negative potentiai, just prior to background discharge, has a diffusion current constant $\left(I_{d}\right)$ equivalent to a $2 e$ transfer, even though the wave slope is near that expected for a reversible $1 e$ process. This probably indicates the preserice of an ECE reaction; the initial, potential-determining, reversible $1 e$ addition is followed by a fast chemical reaction (probably protonation) to produce a species that is immediately reduced in a second le process.

\section{Pyrimidine-4-carboxylic acid}

D.c. polarography. Pyrimidine-1-carboxylic acid in acetonitrile soluition exhibits unusual polarograms at the DME, which essentially consist of three

TABLE 1

Polarographic behavior of substituted pyrimidines in acetonitrile ${ }^{a}$

\begin{tabular}{|c|c|c|c|c|}
\hline Compound & $-E_{1 / 2} / V^{b}$ & $E_{1 / 4}-E_{3 / 4} / \mathrm{mV}$ & $I_{\mathrm{d}} c$ & $\begin{array}{l}\text { Slope of } \\
\text { log plot d }\end{array}$ \\
\hline Pyrimidine & 2.630 & $54(5)$ & $3.39(7)$ & 0.53 \\
\hline 2-Amino- & 2.75 & $58(3)$ & $3.78(12)$ & 0.52 \\
\hline 4-Methyl- & 2.74 & $55(4)$ & $3.71(9)$ & 0.53 \\
\hline 5-Methyl- & 2.64 & $54(3)$ & $3.71(9)$ & 0.57 \\
\hline 2,4-Dimethoxy- & 2.91 & $54(8)$ & $6.55(10)$ & 0.65 \\
\hline 4-Carboxyl-e I & 1.29 & $f$ & $2.17(16)$ & 0.6 \\
\hline $\mathbf{I I}$ & 2.41 & $60(10)$ & $0.42(4)$ & 1 \\
\hline III & 2.57 & $54(6)$ & $3.05(14)$ & 0.52 \\
\hline
\end{tabular}

0.1 if TEAP background electroly te. The numbers in parentheses are the uncertainties (standard deviations) of the last digit(s).

B Potential vs. Ag/ $\mathrm{Ag}^{+}$. Standard deviations are less than $10 \mathrm{mV}$.

$c_{\mathrm{d}}=6 i_{\text {max }} / 7 \mathrm{~cm}^{2 / 3} \mathrm{t}^{1 / 6}$.

d The slope of a plot of $\log i$ vs. $\log h_{\mathrm{Hz}}$. The theoretical value expected for a diffusioncontrolled wave is $\mathbf{0 . 5 0}$; that is, the current is proportional to the square root of the mercury column height.

E. II, and III refer to results for three separate polarographic waves.

r. Very drawn-ont, irregularly shaped wave; $c$, text for description. 
reduction waves. The first wave ac $-1.29 \mathrm{~V}$ is due to a highly irreversible, ie acid (proton) reduction. The second wave is a small prewave $(-2.41 \mathrm{~V})$ antecedent to the third wave $(-2.57 \mathrm{~V})$; both correspond to $1 e$ reduction of the pyrimidine moiety. At longer drop-times, the prewave current is linear with the furst power of mercury column height $(h)$, possibly indicating an adsorption-controlled current. Occurrence of the small prewave between two much larger waves makes evaluation of its current magnitude difficult. Since there are indications that strong adsorption may occur during the acid reduction wave and since electron transfer is already taking place at the solution/ electrode interface, the prewave may correspond to the reduction of an adsorbed species or of some molecules in a preferred orientation at the interface.

Although there is no clear correlation for acids between aqueous $p K_{\mathrm{a}}$ and reduction $E_{1 / 2}$ in acetonitrile [15], stronger acids generally have more positive $E_{1 / 2}$ values; thus, the first acidic hydrogen wave indicates that pyrimidine4 -carboxylic acid is moderately strong for a carboxylic acid. The wave is complex in nature, e.g., about half-way up the wave, the slope changes and becomes less steep. Polarography of a saturated solution (ca. $4 \mathrm{mM}$ ) of the acid shows that this is due to twc incompletely resolved waves (Fig. 1). At long drop-times (low $h$ ), the two waves are well resolved and can be relatively easiiy evaluated. With increase in $h$, the first wave shifts very slightly to more negative potential but remains approximately constant in slope; the second wave shifts to more positive potential and decreases markedly in slope. The net effect at fast drop-times (and at lower concentrations) is to make the acid reduction wave appear to be "bent" in the middle.

The causes for the two waves must, at this point, remain hypotheticai; there are at least four possibilities:

(a) A coupled chemical reaction involving reduction of honded acid (HA) and of dissociated proton $\left(\mathrm{H}^{+}\right)$may occur at the interface. The drop-time dependence of the two waves could be interpreted to indicate $i_{t}$ slow coupled reaction.

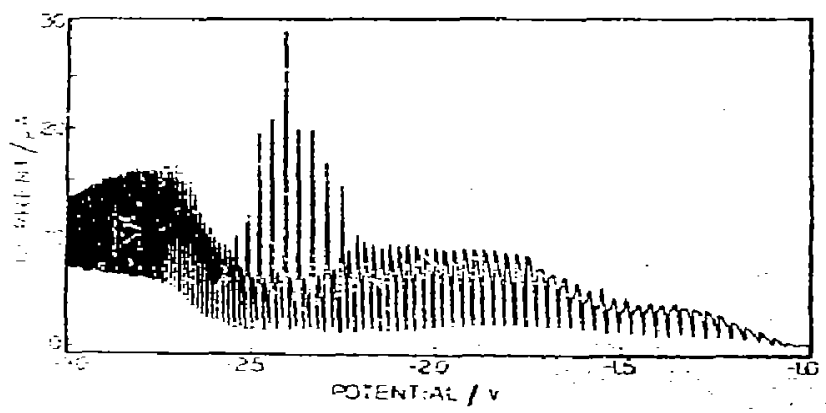

Fig. 1. Polarogram of saturated (ca. $4 \mathrm{mM}$ ) pyrimidine-4-carboxylic acid in acetonitrile. Mercury column height $=38 \mathrm{~cm}$. 
(b) A substantial fraction of hydrogen-bonded dimer, in addition to the monomer, may be present. Dimeric carboxylic acids are known to persist even in the vapor state and in dilute solution in hydrocarbon solvents [15]. The dielectric constant of acetonitrile $(\epsilon=35)$, while not very small, may be sufficiently low to permit substantial dimerization at the interface. The fact that the "bent" acid-reduction wave does not appear to be general (e.g., solutions of benzoic and chiorozcetic acids exhibit drawn-out waves but of normal shape, and Coetzee and Kolthoff [15] report very drawn-out waves for nuorovaleric and phosphoric acids, but no unusual wave shapes for nine Bronsted acids studied), would seem to indicate that explanations (a) and (b) are either incorrect or insufficient.

(c) A zwitterionic or internally hydrogen-bonded form may be reduced as well as the normal carboxylic acid. Such a form, stabilized by nydrozen bonding, should be more difficult to reduce.

(d) The acid reduction may involve strong surface or adsorption phenomena. The distorted shape of the $i-t$ curves between -1.3 and $-1.7 \mathrm{~V}$ may indicate film formation; durin $\vec{b}$ the course of the drop-life, the current reaches a maximum and then decreases, as though reduc ion during the early part of the drop-life were producing a film about the drop which hinders further diffusion of the electroactive species to the electrode surface.

In saturated solution of the acid, the mercury droplets falling during the rising part of the waye and for some distance on the wave plateau do not coalesce on the cell bottom; once the potential corresponding to reduction of pyrimidine moiety is reached, however, the falling mercury droplets again coalesce. On the acid reduction wave plateau from -2.2 to $-2.6 \mathrm{~V}$, alternating drops of high and of low current occur, the only adequate explanation for which is some type of film formation. In the relatively concentrated solution, streaming of the solution past the electrode surface may occur, resulting in an enhanced supply of depolarizer at the electrode surface with a concomitant increase in current. When the mercury drop falls, a film o? the less soluble pyrimidine carboxylate anion remains around the new groving drot, thereby retarding diffusion of more depolarizer to the electrode surface and resulting in a lowered current for the second drop. When this drop falls, it either disrupts this film or pulls it through the solution, thus allowing an increased current for the following drop.

The unusual pattern of droplets of alternating high and low current magnitude is also observed when the DME potential is held constant at several values between -2.3 and $-2.5 \mathrm{~V}$ (and at several mercury column heights), although the current magnitude differences are not quite as large as those observed during a polarogram.

Drop time curves. Since the most plausible explanation for the unusual acidreduction wave for pyrimidine-4-carboxylic acid would seem to be a strong surface or interfacial effect such as adsorption or film formation, drop time curves were obtained. 
Drop time curves for 1 and $5 \mathrm{mM}$ pyrimidine are essentially identical with that for the background electrolyte alone, indicating little or no specific adsorption of pyrimidine.

Except for the sharp depressions at +0.2 and $+0.1 \mathrm{~V}$, the drop time curve for saturated (ca. $4 \mathrm{mM}$ ) pyrimidine-4-carboxylic acid solution (Fig. 2) is quite close (within $0.10 \mathrm{~s}$ ) to that for the background electrolyte alone. Since small changes in the residual water content of the solvent seem to increase slightly the drop-tine in the vicinity of the electrocapillary maximum ( -0.4 to $-1.1 \mathrm{~V}$ ) and in the range of -2.0 to $-2.6 \mathrm{~V}$, it is difficult to say if the small drop-time differences in these two regions are due to water or to the surface effect of pyrimidine-4-carboxylic acid. What is evident, however, is that the unusual current behavior between -2.0 and $-2.5 \mathrm{~V}$ does not have an appreciable effect on the drop time curve, as would be expected if strong specific adsorption were occurring.

The two sharp depressions at positive potential are probably adsorption prewaves just prior to anodic mercury dissolution. Pyrimidine-4-carboxylic acid has the molecular configuration suitable for forming a stable 5-member chelate ring with mercury cations involving the carboxylate oxygen and N(3) of the ring. The potential ano depth of the incision at $+0.19 \mathrm{~V}$ (Fig. 2) are dependent on the concentrai on of the acid. The potential becomes more
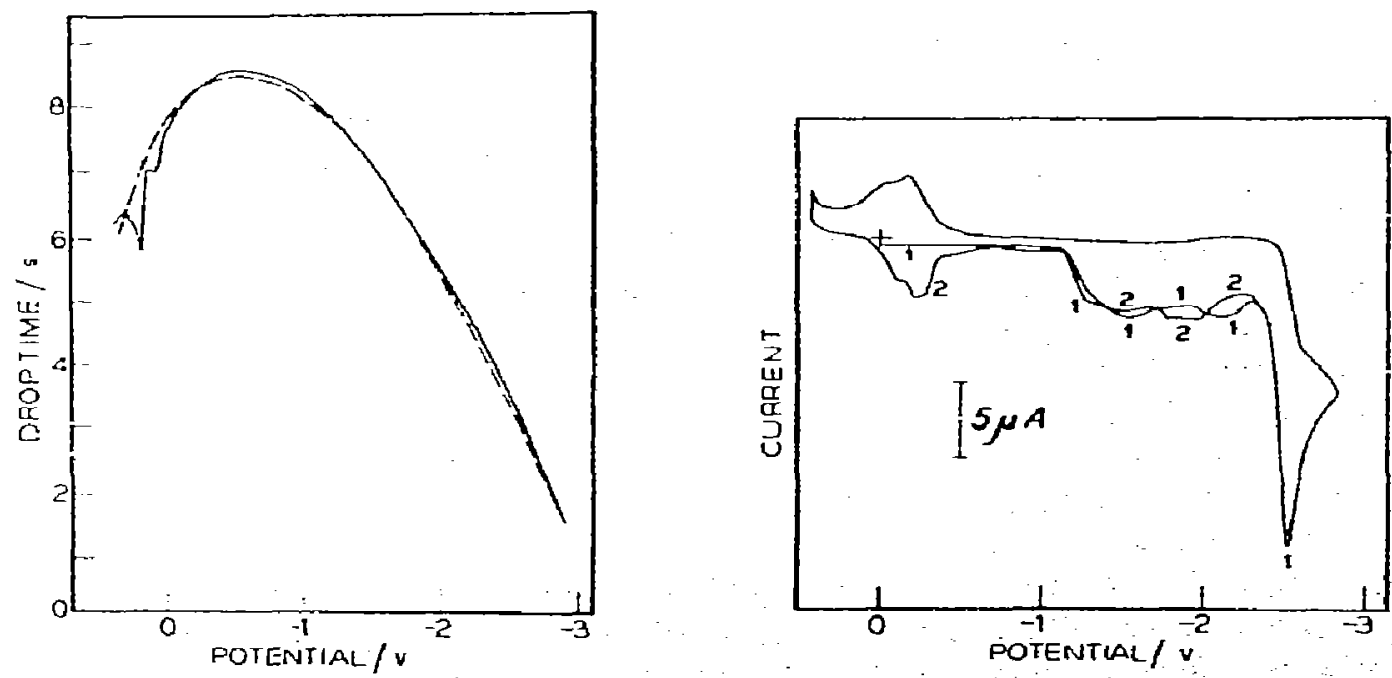

Fig. 2. Electrocapillary curves for saturated (ca. $4 \mathrm{mM}$ ) pyrimidine-4-carborylic acid in acetonitrile (solid line) and for background electroly te alone (0.1 M TEAP); mercury column height $=38 \mathrm{~cm}$.

Fig- 3. Cyclic voltammogram of $0.85 \mathrm{mM}$ pyrimidine-4-carboxylic acid in acetonitrile at the HMDE. Scan rate $=200 \mathrm{mV} \mathrm{s}^{-1}$; arabic numerals refer to the numbers of the scan on successive cycle;. 
negative with increasing concentration: $+0.30,+0.25$, anc $+0.19 \mathrm{~V}$ for 0.15 , 0.76 , and $4 \mathrm{mM}$ solutions, respectively. The depth, as expected, increases with concentration; for the same solutions, the change in drop-time, $\Delta t$, is $0.40,0.82$, and $1.18 \mathrm{~s}$. The smaller incision at ca. $0.1 \mathrm{~V}$ is not visible, at least within experimental accuracy, at 0.15 and $0.76 \mathrm{mM}$ concentration.

Current inagnitude at the DME. The diffusion current constant, $I_{\mathrm{d}}$, for the acid rediction wave of 2.17 is somewhat low for an expected $1 e$ reduction, e.g., values of 3.4 to 3.7 are obtained for $1 e$ reduction of other pyrimidines.

Low $I_{1}$ values have been reported for the irreversible reduction of acids in acetonitrile. For nine acids, $I_{\mathrm{d}}$ generally ranged from 1.9 to 2.8 with extremes of 1.47 (phosphoric acid) and 3.04 (perchloric acid) [15]. While the latter values vaay be partially explained on the basis of differences in diffusion coefficient (perchloric acid, essentially completely dissociated, diffuses as a solvated protion, whereas phosphoric acid may quite possibly exist in solution as long-chain or cyclic hydrogen-bonded oligomers undergoing relatively slow diffusion), other factors must certainly be operative to explain a two-fold change in $I_{\mathrm{d}}$ in what would seem to be superficially similar reactions, i.e., $1 e$ reduction of an acid to form hydrogen gas. These cther factors may involve reversibility or mechanistic considerations, which may tend to lower currents in acetonitrile media below expected levels, e.g., the aging effect [17] observed for solutions of acids in acetonitrile, in which the dissociation of weak acids increases with time.

Cyclic voltammetry. Cyclic voltammograms (Fig. 3) show several peaks for reduction of the acid hydrogen, beginning at about $-1.2 \mathrm{~V}$, and the adsorption prewave at about $-2.2 \mathrm{~V}$ just prior to the large peak at $-2.5 \mathrm{~V}$, which corrssponds to $1 e$ reduction of the pyrimidine moiety. The rather unusual shape of this series of peaks and the fact that the current does not decay appreciably over nearly a one-volt range are further indications of the multiplicity of processes, including probably adsorption and irreversible reduction, involved in the acid-reduction wave for pyrimidine-4-carboxylic acid.

An erratically shaped peak pair at about -0.2 to $-0.5 \mathrm{~V}$ appears to be due to proton reduction, e.g., clipping the cathodic scan before the prewave results in the appearance of these peaks being only slightly altered in snape and magmitude: These peaks correspond to peaks Va and Vc produced on cyclic voltammetry of solutions of benzoic acid and benzoic acid plus pyrimidine, which peaks have been attributed to reduction of acids in acetonitrile [1].

Reperted attempts to prepare a dry crystalline tetraethylammonium salt of pyrimidine-4-carboxylic acid, in order to study the electrochemical behavior of the carboxylate in the absence of the acid-reduction wave, were unsuccessful.

\section{Chloro-and bromoazines}

Since preliminary results indicated that the polarographic reduction of 2chloropyrimidine exhibited some rather unusual phenomena and since the 
results might shed further light on the widely studied carbon-halogen bond fission process $[6,18,19]$, the electrochemical behavior of 2-bromopyrimidine, and model haloazines was also investigated.

Model compounds. The polarographic behavior ('Table 2) of n-bromobutane ( $\mathrm{BuBr}$ ) and bromobenzene ( $\mathrm{PhBr}$ ), which are typical model compounds for the carbon-halogen bond-fission process, is similar to that previously reported for these compounds in nonaqueous media [20-22]: a highly irreversible, diffusion-controlled $2 e$ wave. $E_{1 / 2}$ for $\mathrm{Bu} B \mathrm{r}$ in acetonitrile, however, is approximately $0.18 \mathrm{~V}$ more negative than that reported for DMF solution [21], the most valid explanation for which appears to be differences in the irreversibility of the electron-transfer process.

The polarographic behavior ố 2-bromopyridine also ap(jears to be straigittforward: a $2 e$ irreversible scission of the $\mathrm{C}-\mathrm{Br}$ bond $(-2.47 \mathrm{~V}$, wave $\mathrm{I})$, consequent generation of pyridine itself via protonation, and $2 e$ reduction of the pyridine ( $-2.9 \mathrm{~V}$, wave II). $E_{1 / 2}$ for wave II is identical, within experimental error, with that for pyridine itself [2]. On increasing the pyridine coricentration from 0.07 to $1.5 \mathrm{mM}$, however, $I_{\mathrm{d}}$ for wave II steadily decreases to that expected for an overall 1.5-electron process, possibly indicating partial change of the mechanism to an overall $1 e$ process to produce a free radical, which dimerizes. Previous reports have indicated an overall $2 e$ reduction of pyridine in acetonitrile [23] at $0.6 \mathrm{mM}$ concentration and in DMF [24] at $1 \mathrm{~m} M$ concentration. ESR investigations $[25-27]$, however, have indicated that pyridine radical anions can dimerize ant? rearomalize oxidatively to form 4,4'-bipyridine, which then can be reduced to a radical anicn.

Coulometric electrolyses at controlled electrode potential of solutions ố $\mathrm{BuBr}, \mathrm{PhBr}$, ard 2-bromopyriding confirmed the $2 e$ nature of the $\mathrm{C}-\mathrm{Br}$ fission process (Table 3). Plots of $\log$ (electrolysis carrent) vs. time were linear over nearly $\mathbf{3}$ orders of current magnitude, indicating the absence of slow intervening chemical steps in the cverall process.

The electrolyzed solutions were brownish; the most characteristic feature of their absorption spectra was a strong, broad absorption bared with $\lambda_{\max }$ $\approx 253 \mathrm{~nm}\left(\epsilon:(7\right.$ to 13$) \times 10^{3} 1 \mathrm{~mol}^{-1} \mathrm{~cm}^{-1}$, based on the original concentration of the electroactive compound). Flash distillation of these solutions through a short column produced a clear distillate with an ultraviolet absorption spectrum characteristic of a quantitative yield of the parent compound for the benzene and pyridine derivatives. There was no spectrophotometric evidence for the formation of bipyridine in the electrolyzed solutions, either before or after distillation. The brownish colos of the electrolyzed sclutions and the strong absorption at $253 \mathrm{~nm}$ are undoubtedly due te polymeric or other non-volatile products from decomposition of solvent and/or background electroly te during electrolysis.

2-Bromo-and 2-bhloropyrimidine. The electrochemical behavior of 2 -bromo and 2-chloropyrimidine is considerably more complex than that of the bromo 


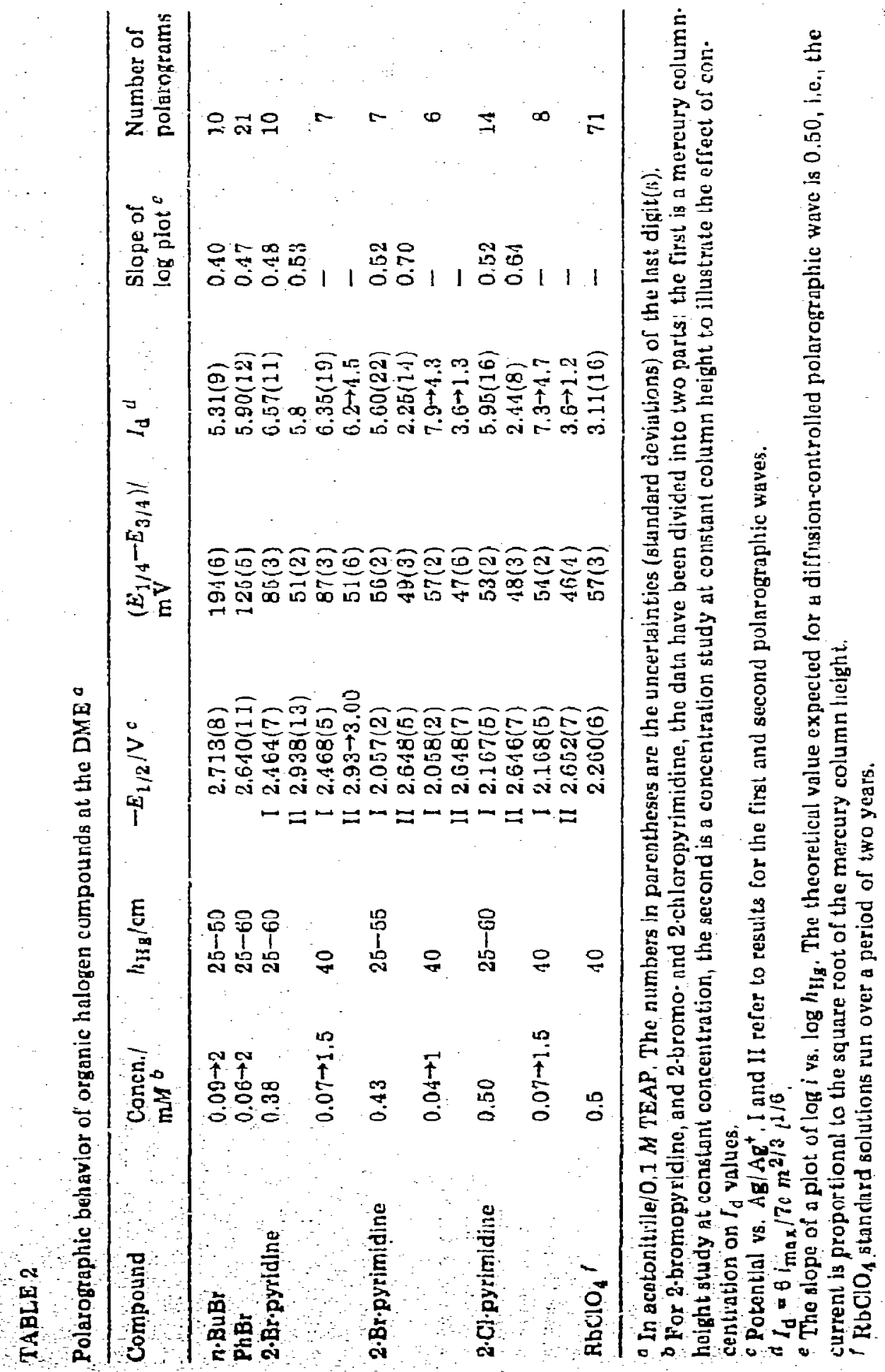




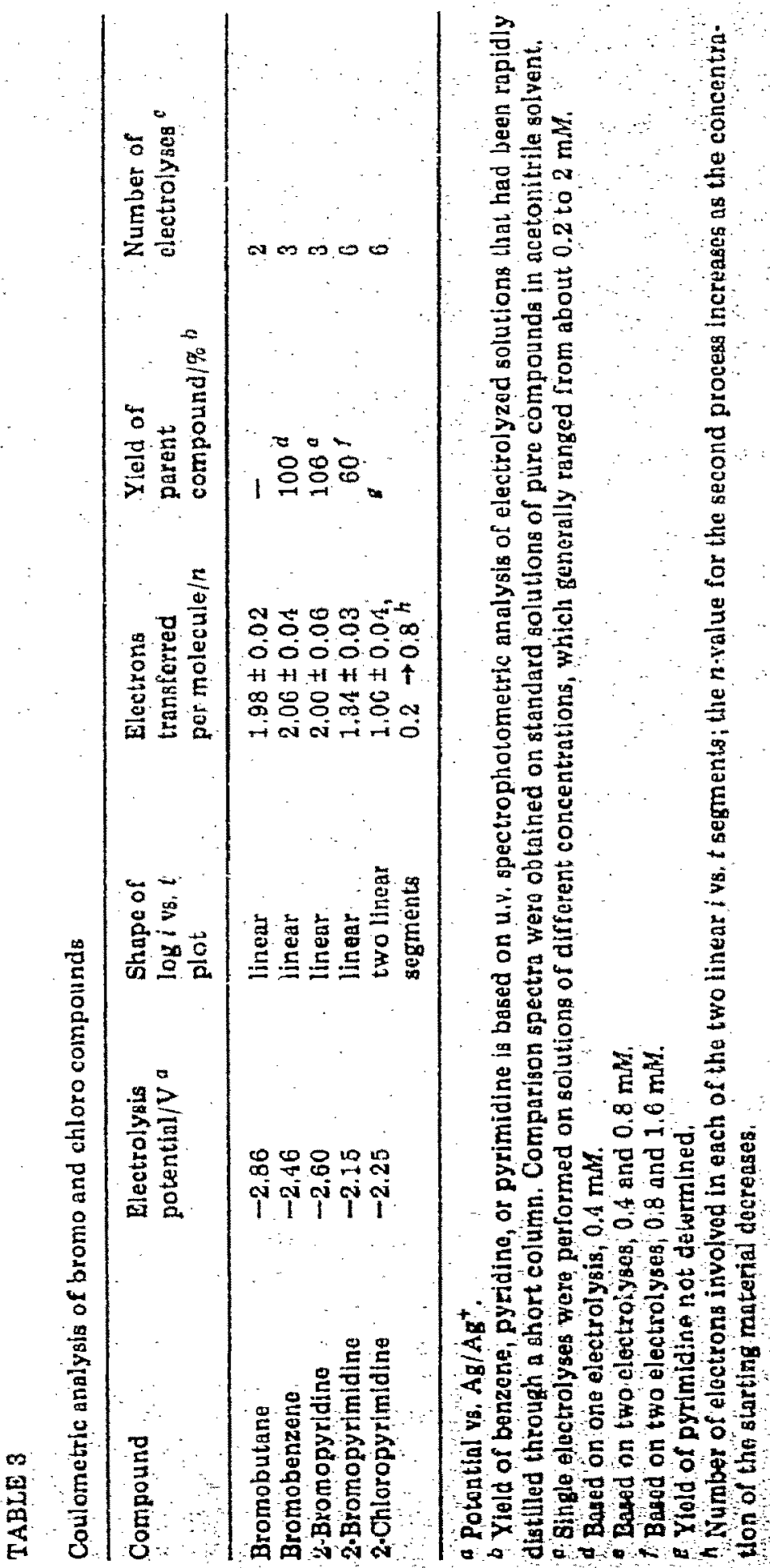


compounds just discussed. Under polarographic conditions at about $0.5 \mathrm{mM}$ concentration, these two pyrimidines are reduced in two steps (Table 2): an initial apparent $2 e$ process corresponding to the $\mathrm{C}-\mathrm{X}$ cleavage (wave $\mathrm{I}$ ), followed by a 1e reduction of the pyrimidine electrozenerated in the wave $I$ process. $E_{1 / 2}$ for wave II is identical, within experimental error, with that for pyrimidine itself [2]; Although wave I seems to be an overall $2 e$ process, its slope of about $55 \mathrm{mV}$ is indicative of a reversible $1 e$ potential-determining step $E_{i / 2}$ and $I_{d}$ values are independent of $h$; with increasing concentration (0.05 to $2 \mathrm{mM}), I_{\mathrm{d}}$ decreases and then levels off (Fig. 4 ).

Coulometry and spectroscopic studies. Coulometry of 2-chloropyrimidine solutions on electrolysis at potentials on the wave-I plateau indicate similar results (Fig: 4; Table 3). The coulometric $n$ for concentrations greater than about $0.5 \mathrm{mM}$ is roughly constant at $1.36 \pm 0.07$ electrons/molecule, increasing to nearly $2 e$ as the concentration is decreased to $0.08 \mathrm{mM}$. Plots of $\log$ (electrolysis current) vs. time consist of two linear segments: a rapid 1.0 -transfer, accounting for the first segment, and a slower process accounting for the excess fractional electron (Fig. 5). Potentiometric titration of an electrolyzed solution (originally $2.88 \mathrm{mM}$ 2-chloropyrimidine) with $\mathrm{AgNO}_{3}$ indicated a $97 \pm 5 \%$ yield of $\mathrm{Cl}^{-}$ion.

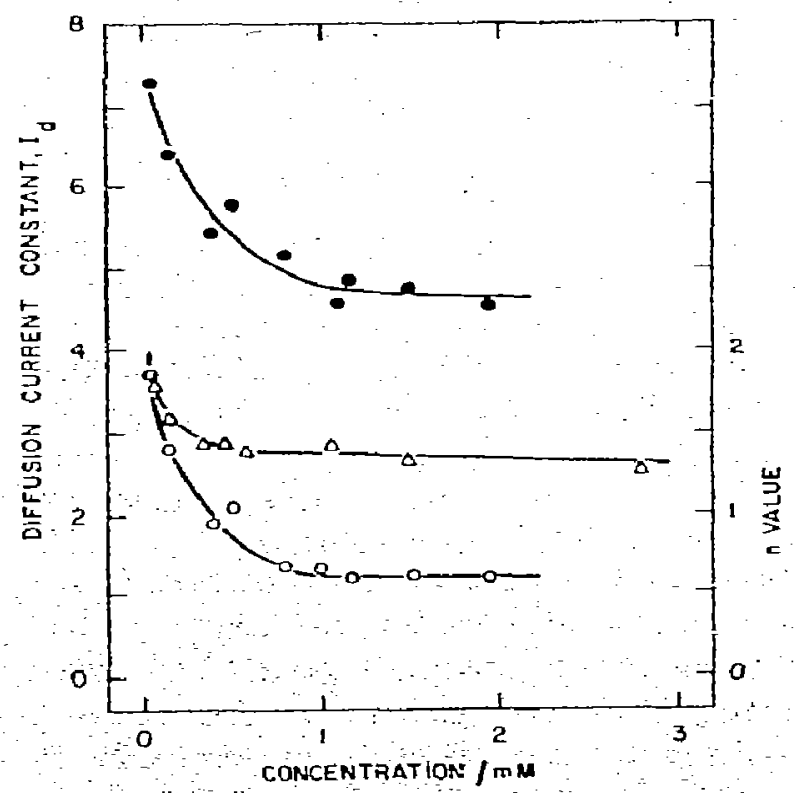

Fig- 4 Variation with concentration of the diffusion current constants for the two 2-chloropyrimidine reduction waves and of the coulometric $n$-values for the $c-c$ bond fission proces (- $I_{d}$ for wave Iat $E_{1 / 2}-2.17 V_{;}(0) I_{d}$ for wave Ir at $E_{1 / 2}=264 \mathrm{~V}$ mercury column height $\mathbf{4 0} \mathrm{cm} ;(\Delta)$ coulometric $n$-values for the wave $I$ process; electrolysis potential $=-2.25 \mathrm{~V}$. 
The exact electrolysis potential has little apparent effect on $n$; for $0.58 \mathrm{~m} M$ 2-chloropyrimidine, $n=1.35,1.38$, and 1.40 for $E=-2.18,-2.25$, and -2.40 $\mathrm{V}$, respectively.

Polarograms of electrolyzed solutions of 2-chloropyrimidine exhibit a reduction wave at $-2.63 \mathrm{~V}$ due to elestrogenerated pyrimidine, and two anodic waves at -0.15 and $-0.45 \mathrm{~V}$ due to oxidation of mercury in the presence of chloride ion. Millimolar solutions of tetraethylammonium chloride in TEAP background exhibit very similar anodic waves at the same potentials. $I_{\mathrm{d}}$ values for all three waves decrease with increasing concentration in much the same manner as the $I_{\mathrm{d}}$ plots of Fig. 4. The $E_{1 / 2}$ values for the two anodic waves are also functions of concentration, as would be expected for anodic adsorption waves. Generally, the $I_{\mathrm{d}}$ values increase with decreasing concentration; simple dilution of solutions with acetonitrile results in increased $I_{d}$ values for the two waves. The higher $I_{\mathrm{d}}$ values for the pyrimidine reduction wave for electrolyzed solutions of low concentration probably result from the ECE process in the reduction of pyrimidine [1], in which the electrogenerated pyrimidine radical anion is protonated by residual water and/or solvent and then further reduced in a second $1 e$ process. Since the pyrimidine concentration is so low, the rate of the ECE process becomes competitive with the fast second-order dimerization reaction. There is no evidence for the formation of a neutral bipyrimidine compound in elestrolyzed solutions as this should be reducible within the available potential range, e.g., $E_{1 / 2}$ for reduction of 2,2'-bipyridine in DMF is over $500 \mathrm{mV}$ more positive than that of pyridine [24]; the only reduction wave observed is that due to pyrimidine itself, whose current magnitude indicates a more or less quantitative yield of pyrimidine.

Electrolyzed solutions of 2-chloropyrimidine exhibit a broad band near $310 \mathrm{~nm}\left(\epsilon=2700\right.$ to $\left.47001 \mathrm{~mol}^{-1} \mathrm{~cm}^{-1}\right)$, based on the original concentration), as well as the characteristic spectrum of pyrimidine itself in acetonitrile $\left(\lambda_{\max }(\epsilon)=233 \mathrm{~s}(1610), 238(2050), 242(2020), 248 \mathrm{~s}(1490)\right)$. There is no ultraviolet indication of residual 2-chloropyrimidine $\left(\lambda_{\max }(\epsilon)=245 \mathrm{~s}(2300)\right.$, $251(2600), 256 s(1990))$ or of the formation of $2,2^{\prime}$-bipyrimidine $\left(\lambda_{\max }(\epsilon)=\right.$ $241(15,900)$ in aqueous media [11]).

In contrast to the behavior of the 2-chloro compound, 2-bromopyrimidine exhibits linear $\log i$ vs. time electrolysis plots (Fig. 5) for solutions from 0.05 to $1.6 \mathrm{~m} M ; n$ is constant at $1.34 \pm 0.03$. Spectrophotometric analyses of flash-distilled electrolyzed solutions, however, indicate only a $60 \%$ yield of pyrimidine, as opposed to the $100 \%$ yield of the parent compound for $\mathrm{BuBr}$ and $\mathrm{PhBr}$. Addition of water to electrolysis solutions has no effect on $n$ values; for electrolysis of $0.80 \mathrm{mM}$ solutions, $n=1.36 \pm 0.01$ in nominally "dry" acetonitrile $\left(c_{\mathrm{H}_{2} \mathrm{O}} \approx 5 \mathrm{mM}\right)$, or with 50 or $130 \mathrm{mM}$ added water. Electrolyzed solutions are brownish. The most characteristic feature of the ultraviolet spectrum is a broad absorption band of $\lambda_{\max }=308 \mathrm{~nm}\left(\epsilon \approx 70001 \mathrm{~mol}^{-1}\right.$ $\mathrm{cm}^{-1}$, based on the original 2-bromopyrimidine concentration), which obscures the characteristic spectrum of pyrimidine itself until the solutions are 

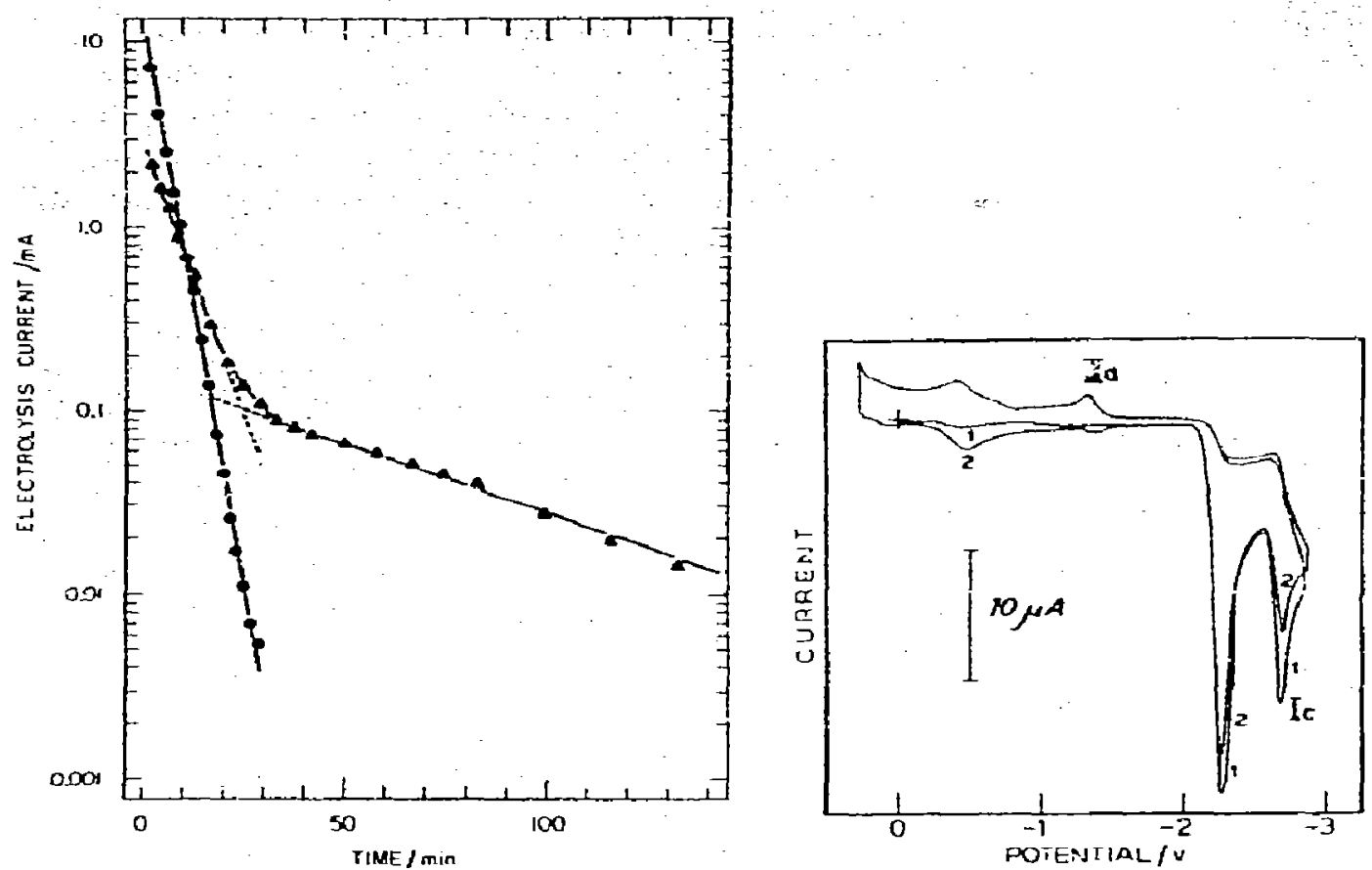

Fig. 5. Variation of current with time during the controlled potential electrolysis of 2-bromoand 2-chloropyrimidine. (•) Electrolysis of $0.86 \mathrm{mM}$ 2-bromopyrimidine at - $2.25 \mathrm{~V}$; $n_{\text {measured }}=1.27$ e/molecule. $(\bullet)$ Electrolysis of $0.86 \mathrm{mM} 2$-chloronyrimidine at $-2.25 \mathrm{v}$; $n_{\text {measured }}=1.42$ e/molecule.

Fig. 6. Cyclic voltammogram of $0.57 \mathrm{mM}$ 2-chloropyrimidine at the HMDE. Scan rate = $200 \mathrm{mV} \mathrm{s}^{-1}$; arabic numerals reier to the number of the scan on successive cycles; peaks are identified in the text.

flash-clistilled. The absorbance of electrolyzed solutions at $308 \mathrm{~nm}$, however, is dependent on the water level of the solvent, increasing from about $\epsilon=$ $70001 \mathrm{~mol}^{-1} \mathrm{~cm}^{-1}$ for nominally dry acetonitrile to about 12000 for 130 mM added water.

Cyclic voltammetry. Cyclic voltammograms of 2-chloropyrimidine (Fig. 6) show the reduction of the $\mathrm{C}-\mathrm{Cl}$ bond prior to the peak corresponding to reduction of the pyrimidine moiety (Peak Ic). As would be expected for an electrode reaction involving $\mathrm{C}-\mathrm{Cl}$ bond cleavage, the process is highly irreversible, e.g., no complementary anodic peak for the reoxidation appears even at high scan rates. With increase in scan rate, $v$, from 0.2 to $140 \mathrm{~V} \mathrm{~s}^{-1}$, the peak current function, $i_{\mathrm{p}} ! c v^{1 / 2}$, for the $\mathrm{C}-\mathrm{Cl}$ scission peak decreases from about 95 to 10 , whereas that for peak Ic remains constant at $37 \pm 2$.

Peak IIla is due to the irreversible oxidation of a pyrimidine anionic dimer produced after $1 e$ reduction of pyrimidine [1]. 
The peaks at about $-0.5 \mathrm{~V}$ in Fig. 6 correspond to the anodic waves observed on polarography of electrolyzed solutions, i.e., are due to oxidation of mercury in the presence of chloride ion. Reversal of the scan at a potential just prior to peak Ic (about $-2.5 \mathrm{~V}$ ) produces these peaks essentially unchanged in appearance and magnitude, indicating that they appear as a result of the first electron transfer process, i.e., scission of the $\mathrm{C}-\mathrm{Cl}$ bond.

Mechanism of carbon-halogen bond fission. The most reasonable explanation for the observed behavior of 2-bromo- and 2-chloropyrimidine in acetonitrile is that these two compounds are initially reduced in a reversible, $1 e$ addition with a subsequent, fast scission to produce halide ion and pyrimidine free radical. The wave slope for the poiarographic reduction (Table 2) is quite close to the theoretically expected $56 \mathrm{mV}$, as opposed to the more drawn-out, "irreversible" $2 e$ waves for $\mathrm{BuBr}, \mathrm{PhBr}$, and 2-bromopyridine. This can be interpreted as being due to the initial addition of an electron to the lowest $\mathrm{C}-\mathrm{Br} \sigma *$ orbital in the three model compounds, but to the lowest $\pi^{*}$ orbital in the pyrimidine compounds. Fukui et ai. [28], for example, have correlated the $E_{1 / 2}$ values for reduction of haloalkanes and halobenzenes with the lowest $\sigma^{*} \mathrm{C}$-X orbital; it is well known that substitution of $\mathrm{N}$ for $\mathrm{CH}$ in aromatics has the effect of lowering the energies of $\pi *$ orbitals.

The pyrimidine free radical thus generated must be a very transient species, as indicated by the non-appearance of a cyclic voltammetric peak that could be attributed to its oxidation. Most probably, it is deactivated by hydrogen atom abstraction from the soivent or background electrolyte to form pyrimidine which is then reduced at more negative potential (ca. $-2.63 \mathrm{~V})$. The preponderance of experimental evidence indicates quantitative formation of halide ion and pyrimidine in a 1e first step.

The "excess" electrons, i.e., that amount greater than Ie/molecule, must arise from secondary electrochemical reactions, probably involving the solvent, background electrolyte, and residual water. The presence of at least two such reactions is indicated by the data, e.g., the differing shapes for the $\log i$ vs. $t$ electrolysis plots for bromo- and chloropyrimidine evelı when the electroly oes are performed at the same potential and the dependence on the "backgrouna" electrolysis reactions and products on the residual water level of the solvent as indicated hy the variation in ultraviolet spextra of electrolyzed solutions of 2-bromopyrimidine with added water. $\mathrm{BuBr}$ and $\mathrm{PhBr}$, which clearly involve $2 e$ and protor abstraction, result in electrolyzed solutions with $\lambda_{\operatorname{mex}}$ at $.253 \mathrm{~nm}$, as compared to solutions with $\lambda_{\max }$ at about $208 \mathrm{~nm}$ for the pyrimidine compounds.

The behavior for the 2-halopyrimidines is quite similar to that reported by Nadjo and Saveant [29] for bromo- and chloro-substituted benzophenone, in which the experimental observations are consistent with an expulsion of the halide ion from the anion radical initially formed, followed by abstraction of a hydrogen atom from the solvent. For example, coulometric analysis of $2 \mathrm{~m} M$ solutions with short electrolysis durations (about $15 \mathrm{~min}$ for $90 \%$ con- 
sumption of the original compound; electrolysis conditions similar to ours) resulted in an $n$-value of about 1.2; with slower electrolysis conditions, i.e., $t_{905} \approx 3 \mathrm{~h}$, the $n$-value was close to two. Voltammetric studies on the benzophenones were apparently not performed on solutions as dilute as some of the ones in this study (down to $0.04 \mathrm{mM}$ ). Evidence for the existence of the intermediate benzophenone radical has been demonstrated by trapping with a nucleophilic reagent during the course of electrolysis [30].

Knowledge of the exact nature of the "background" reactions in acetonitrile must await further, more detailed studies, although there has already been considerable discussion of the solvent/electrolyte reactions in acetonitrile and DMF $[2,31-36]$.

\section{ACKNOWLEDGEMENTS}

Acknowledgement is made (by JEO) to the Donors of the Petroleum Research Fund, administered by the American Chemical Society, for partial support of this research, and (by PJE) to the National Science Foundation for partial support of the work described.

\section{REFERENCES}

1 J.E. O'Reilly and P.J. Elving, J. Amer. Chem. Soc., 93 (1971) 1871.

2 J.E. O'Reilly and R.J. Elving, J. Amer. Chem. Soc., 94 (1972) 7941.

3 K.S.V. Santhanam and P.J. Elving, J. Amer. Chem. Soc., 95 (1973) 5482.

4 K.S.V. Santhanam and P.J. Elving, J. Amer. Chem. Soc., 96 (1974) 1653.

5 P.J. Elving, J.E. O'Reilly and C.O. Schmakel, in D. Glick (Ed.), Methods of Biochemical Analysis, Vol. 21, Wiley, New York, 1973, pp. 287-465.

6 C.K. Mann and K.K. Barnes, Electrochemical Reactions in Non-aqueous Systems, Marcel Dekker, New York, 1970, pp. 201-244.

7 M.R. Rif, in M.M. Baizer (Ed.), Organic Electrochemistry, Marcel Dekker, New York, 1973 , pp. 279-314.

8 B. Czochralska, Roczn. Chem., 44 (1970) 2207.

9 M. Wrona and B. Czochralska, Acta Biochim. Polon., 17 (1970) 351.

10 I.C. Kogan, R. Minin and C.G. Overbenger, Org. Syn., 35 (1955) 34.

11 D.D. Bly and M.G. Mellon, J. Org. Chem., 27 (1962) 2945.

12 D.J. Brown, Nature, 165 (1950) 1010.

13 J.E. O'Reilly, Ph.D. Thesis, University of Michigan, Ann Azbor, Mirhigan, 1971.

14 R C. Iarson, R.T. Iwamoto and R.N. Adams, Anal. Chim. Acta, 25 (1961) 371.

15 J.F. Coetzee and I.M. Kolthiff, J. Amer. Chem. Soc., 79 (1957) 611 C.

16 J.D. Roberts and M.C. Caserio, Basic Principles of Organic Chemistry, W.A. Benjamin, New York, 1964, p. 509.

17 Li.L. Kolthoff, S. Bruckenstein and M.K. Chautooni, Jr,, J. Amer Shem. Soc., 83 (1961) 3927.

18 P.J. Elving, Ree Chem. Progr., 14 (1953) 99.

19 M. von Stackelberg and W. Stracke, Z. Elektrjchem., 53 (1949) 118.

20 J.W. Sease, F.G. Burton and S.L. Nickol, J. Amer. Chem. Goc., 90 (1968) 2595.

21 F.d. Lambert, J. Org. Chem., 31 (1966) 4184.

22 S. Wawzonek and J.H. Wagenknecht, J. Electrochem. Soc., 110 (1963) 420. 
23 S. Millefiori, J. Heterocyclic Chem., 7 (1970) 145 .

24 K.B. Wiberg and T.P. Lewis, J. Amer. Chem. Soc, 92 (1970) 7154 .

25 J. Chaudhuri, S. Kume, J. Jagur-Grodzinski and M. Szwarc, J. Amer. Chem. Soc,, 90 (1968) 6421 .

26 R.L. Ward, J. Amer. Chem. Soc., 83 (1961) 3623.

27 A. Carrington and J. dos Santos-Veiga, Mol. Phys.; 5 (1962) 21.

28 K. Fukui, K. Morokuma, H. Kato and T. Yonezawa; Bull. Chem. Soc: Japan, 36 (1963) 217.

29 L. Nadjo and J.M. Saveant, J. Electroansl. Chem., 30 (1974) 41.

30 J. Pinson and J.M. Saveant, Chem. Commun., (1974) 933.

31 J.R. Jezorek and H.B. Mark, Jr., J. Phys Chem., 74 (1970) 1627.

32 I.M. KolthoIf, M.K. Chantooni, Jr. and H. Smagowski, Anai. Chem, 42 (1970) 1622.

33 I.L. Webb, C.K. Mann and H.M. Walborsky, J. Amer. Chem. Soc., 92 (1970) 2042.

34 A.J. Fry and F.G. Reed, J. Amer. Chem. Soc, 93 (1971) 553.

35 A.J. Fry and R.G. Reed, J. Amer. Chem. Soc, 94 (1972) 8475.

36 M.R. Rifi and F.H. Covitz, Iatroduction to Organic Electrochemistry, Marcel Dekker, New York, 1974, pp. 194-219. 